\title{
Retrieving Broken Metallic Instruments from Root Canal by Using the Ultrasound System and Endodontic Microscope
}

\author{
IREN MORARU ${ }^{1}$, ANCA GHEORGHE ${ }^{1 *}$, ANA MARIA RACA ${ }^{1}$, CEZAR DIACONU ${ }^{2}$, OANA DIACONU ${ }^{1}$, LELIA GHEORGHITA ${ }^{1}$ \\ 'University of Medicine and Pharmacy, Dental Medicine Faculty, 2 Petru Rares Str., 200349, Craiova, Romania \\ ${ }^{2}$ WhiteKiss Clynic, 21 Mai Blvd, 200638, Craiova, Romania
}

\begin{abstract}
During root canal instrumentation several accidents may occur, one of them being the separation of the instrument.The chemical structure of metallic boken instrumenthas an important role in the therapeutic approach. Due to metal fatigue, over instrumentation, incorrect speed, bad technique, and several other reasons, the endodontic instruments, manual or rotative, maybreak inside the rootcanal. The broken piece usually gets stuck inside the dentine walls. Several years ago, such accident was equal to the loss of the tooth, but nowadays, with the use of the endodontic microscope and ultrasonic tips, the teeth can be fully restored as the separated instrument can be removed safely.
\end{abstract}

Keywords: broken files, endodontic microscope,chemical structure of broken instrument, ultrasonic tips

During root canal treatment several accidents may occur, mentioning root perforation, ledge formation or instrument fracture or separation. The type of alloy of the broken instruments, but also the chemical structure of these instruments, are involved in therapeutic algorithm. These accidents often lead to endodontic treatment failure by reducing the effectiveness of the elimination of intracanal microorganisms that are located in the portions of the root anal hat become inaccessible [1]. The endodontic treatment depends on the cleaning and shaping of the root canals and an instrument fracture hinders the endodontic treatment making it more complex.

There are several reasons why an instrument can fracture within the root canal, such as: overinstrumentation, loss of tactile sensation, increased speed with rotary instruments, improper techniques, curved canals or accessory canals, metal fatigue due to repeated sterilization [2]. While the increased usage of the rotary files gives an obvious increased rate of this kind of broken files, we must consider that anything that is being worked inside the root canal can getbroken, namely Lentulo, GlideGlidden bus, manual files (especially NiTi) [3].

When instrument separation occurs, the clinician has the following choices: - leaving the instrument in the canal, bypassing and obturating the canal, or retrieving the file segment either surgically or nonsurgically [4].

\section{Experimental part}

Material and methods

The study was done in the Endodntics Clinic of UMF Craiova in colaboration with private clinic in Craiova. The study was approved by the Etichal Commity of UMF Craiova. The patients were informed about the study and they they signed an informed consent. We selected several cases with various broken metallic instruments on the root canals.All cases were handled under microscope magnification, using $\mathrm{K}$ files and ultrasonic with special tips: ProUltra Endo Tips no 3, 4, 5, Dentsply Tulsa Dental. Therefore we used the following means: Operative Microscope Global G3, Ultrasonic scaler DTE D7, Start X Kit Dentsply Maillefer for removal of old root canal filling and broken files, Endo tip E4 Woodpecker for removal of broken files, $\mathrm{K}$ files no 08, 10, 15, 20 (Dentsply Maillefer),
Rotary instruments D system(D1, D2, D3) for retreatment Dentsply Maillefer, Pro Taper Next system (X1, X2, X3, X4, $X 5)$ Dentsply Maillefer for shaping, $\mathrm{NaOH} 5 \%$, Citric acid 10, EDTA sol $17 \%$ for cleaning, Rubber dam (Colthene).

Case no. 1

Irreversible symptomatic pulpitis tooth 2.5 under metallic-ceramic bridge. The referral dentist initiated the root canal treatment through the crown due to financial reasons but because of complex internal anatomy with severe curvature of the root canals a hand file was broken. (fig. 1)

After isolation with rubber dam the access cavity was improved using the access cavity kit burs (Dentsply Maillefer) under magnification (operative microscope Global G3) (fig. 2). Scouting the root canal was performed using K-Files no 08, 10, 15 (Dentsply Maillefer) until the blockage caused by the broken file. Preflaring and enlargement of the coronal two thirds of the root canal was performed using Gates Glidden burs and shaping SX Protaper (Dentsply Maillefer) in order to visualize and gain access to the broken file (fig.3). Under microscope magnification the broken file was removed using ultrasonic and special tips (ProUltra Endo Tips no 3, 4, 5, Dentsply

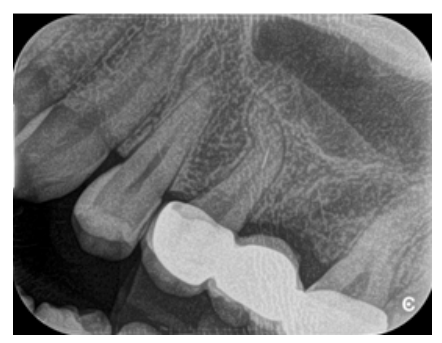

Fig. 1. Preoperative retro alveolar $\mathrm{x}$-ray of $2^{\text {nd }}$ bicuspid

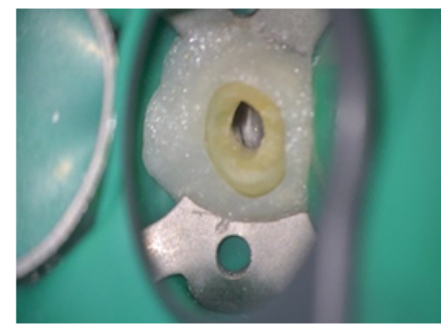

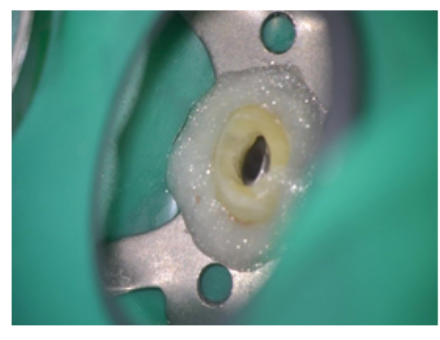

Fig. 2. Access cavity through the crown
Fig. 3. Visualization of the broken file

* email: ancaggheorghe@gmail.com, Phone:+40787821334 
Tulsa Dental) and the ledge created initiallywas by-passed using pre-curved K-Files no 06, 08 until we reached the working length confirmed by apex locator (fig. 4). Root canal shaping was performed using ProTaper Next system, $\mathrm{X} 1, \mathrm{X} 2 \mathrm{Ni}-\mathrm{Ti}$ and cleaning using $\mathrm{NaOH}$ 5\%, EDTA, saline solution and $\mathrm{CHX} 2 \%$. Root canal filling was performed using warm vertical condensation of gutta-percha and sealer. Root canal treatment was completed by aligning the coronal access cavity using light curing composite resin and post-operative radiography (fig. 5).

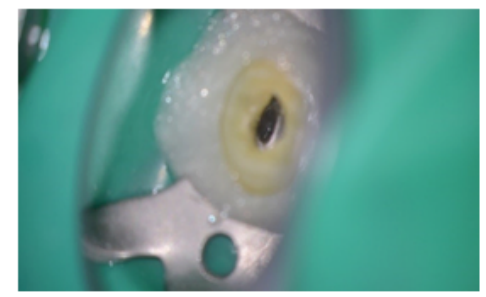

Fig. 4 Removal of the broken file

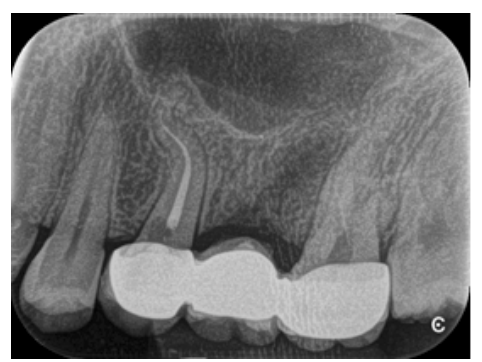

Fig. 5 Postoperative $x$-ray

\section{Case no 2}

Diagnosis: Asymptomatic chronic apical periodontitis with previously initiated root canal treatment. Broken file on the distal root canal of 46. (fig. 6)

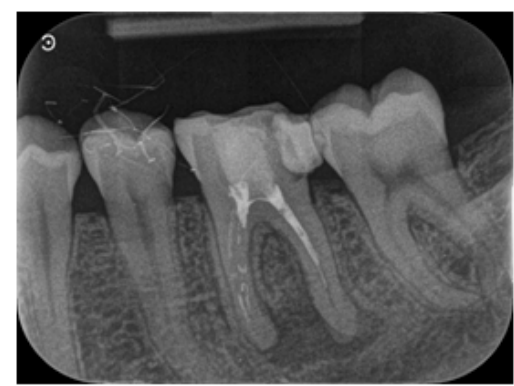

Fig. 6. Preoperative $\mathrm{x}$-ray of $1^{\text {st }}$ molar -

Asymptomatic chronic apical periodontitis

After isolation with rubber dam (fig. 7) the old coronal filling was removed and the access cavity was completed according to known principles with the reconstruction of the distal wall with glass ionomer cement (fig. 8). The old gutta-percha was removed from the root canals using rotary Ni-Ti files (d System D1, D2, D3 ProTaper Dentsply

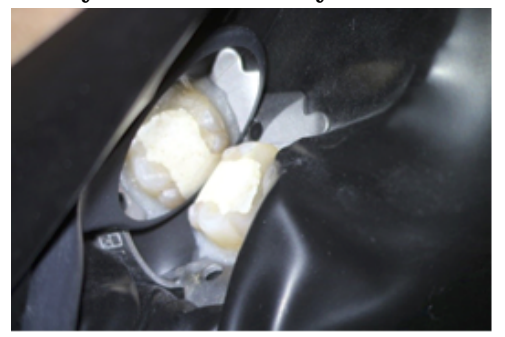

Fig. 7. Isolation with rubber-dam

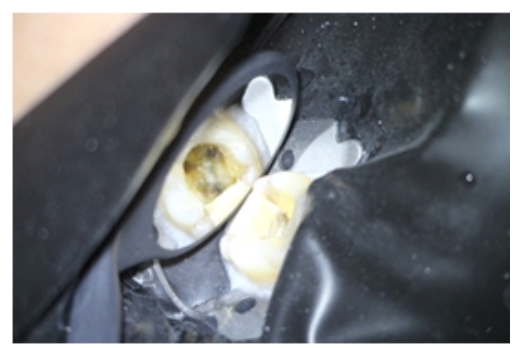

Fig. 8. Removal of the filling and preparation of the access cavity
Maillefer) and Eucalyptoil as a solvent under heavy irrigation with $\mathrm{NaOH} \mathrm{5 \%} \mathrm{(fig.} \mathrm{9).} \mathrm{The} \mathrm{ability} \mathrm{to} \mathrm{access} \mathrm{and} \mathrm{remove}$ the broken file on the distal root canal in the middle third of the root is influenced by the cross-sectional diameter, length and curvature of the root, therefore is very important to visualize and expose at least one third of the overall length of the obstructing instrument.

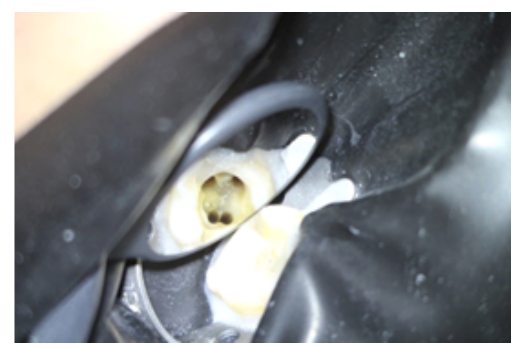

Fig. 9. Pre-flaring and enlargement of the canals

We used Gates Glidden burs in order to create sufficient space in the coronal third of the root canal, with a brushing technique, and each larger $\mathrm{GC}$ is stepped out of the canal to create a smooth flowing funnel that is largest coronally and tapers dow $n$ to the head of the broken instrument.

Under magnification we used ultrasonic techniques together with abrasively-coated ultrasonic tips (ProUltra Endo Tips no 3, 4, 5, Dentsply Tulsa Dental. The final filling was done using warm guthaperca (fig. 10) and we verified it in a post-operative radiography (fig.11).

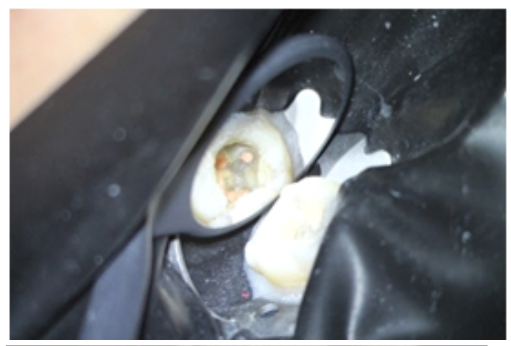

Fig. 10. Root canal fillingwarm vertical condensation of guttapercha and sealer

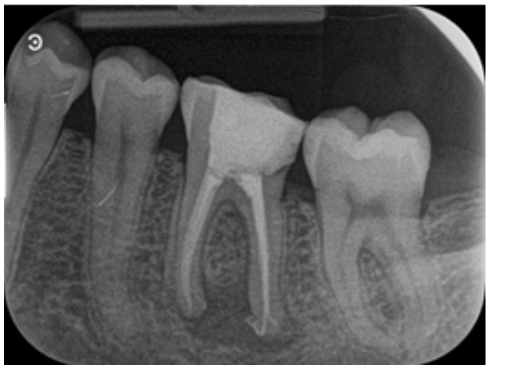

Fig. 11. Post-operative radiography

\section{Case no 3}

Diagnosis: Asymptomatic chronic apical periodontitis with previously initiated root canal treatment tooth 1.6. Broken file on the mesio-buccal root canal (fig.12).

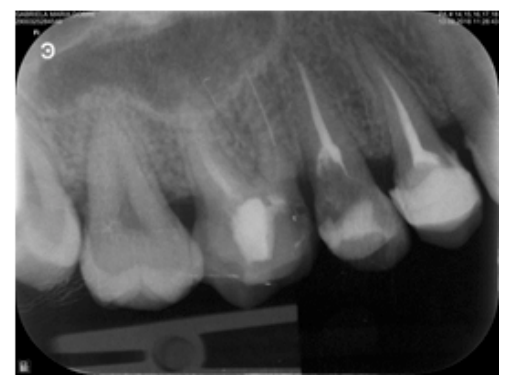

Fig. 12. Pre operative radiography

After isolation with rubber dam the old coronal filling was removed and the access cavity was completed according to known principles with the reconstruction of the mesial wall with glass ionomer cement. The old guttapercha was removed from the root canals using rotary $\mathrm{Ni}$ Ti files (D System D1, D2, D3 ProTaper Dentsply Maillefer) and Eucalypt oil as a solvent under heavy irrigation with $\mathrm{NaOH} 5 \%$ using ultrasonic activation. (fig.13) We identified 


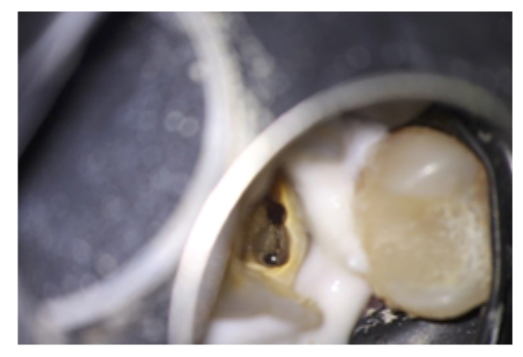

Fig. 13. Rubber dam isolation

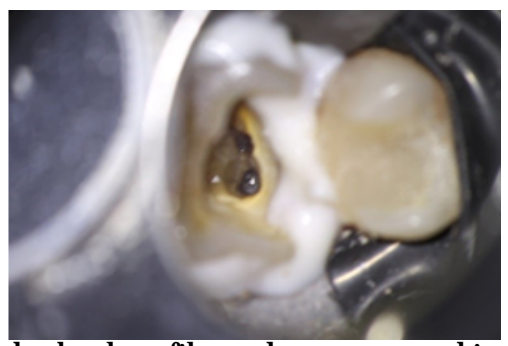

Fig. 14. The broken file on the mesiobuccal root canal

the broken file and we removed it using the ultrasonic tips (fig. 14). After removal of the old root canal filling material we identified the second mesio-buccal root canal and they were all shaped using the Pro-Taper Next system with $\mathrm{NaOH} 5 \%$ irrigation under magnification and ultrasonic activation. Root canal filling was performed using warm vertical condensation of gutta-percha and sealer (fig. 15). Root canal treatment was completed by sealing the coronal access cavity using light curing composite resin and postoperative radiography (fig.16).

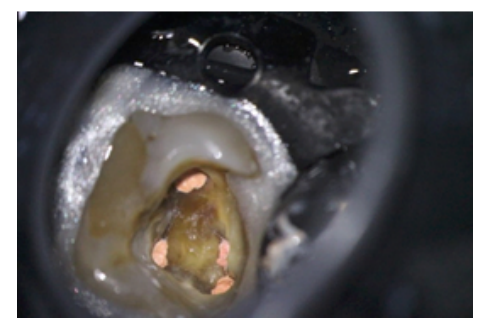

Fig. 15. Clinical aspect after root canal filling

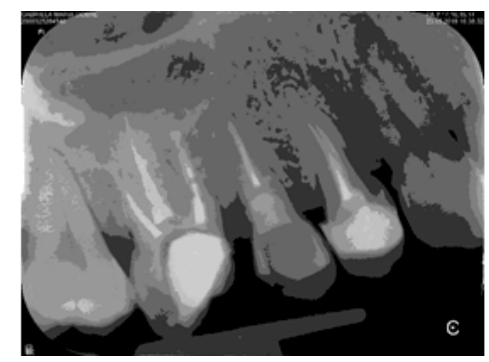

Fig. 16. Post operative radiography

\section{Case no 4}

Diagnosis. Symptomatic chronic apical periodontitis with previously initiated root canal treatment tooth 2.6. Broken file on the mesio-buccal root canal (fig. 17, 18).

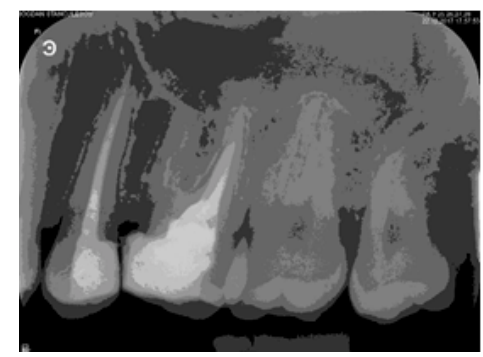

Fig. 17. Pre operative radiography

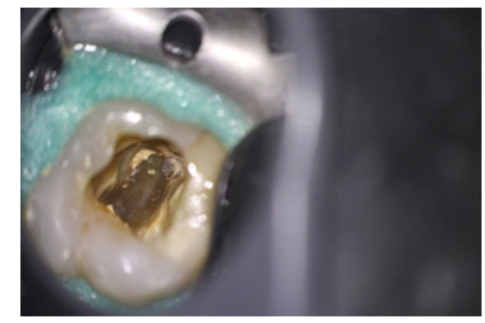

Fig. 18. Initial aspect after isolation
We followed the same therapeutic protocol in cleaning and shaping but the root canal filling was performed on a second appointment due to persistence of leakage in the canals and severe pain on 2.6 on vertical percussion. After the removal of the broken file on the mesio-buccal canal (fig. 19) the shaping and cleaning was performed using the Pro-Taper Next system using $\mathrm{NaOH} 5 \%$ and ultrasonic activation. For the temporary root canal filling we used a paste with calcium hydroxide for 14 days. After that period of time the tooth was pain free so we removed the calcium hydroxide paste using citric acid $10 \%$ and the root canal filling was performed using warm vertical condensation of gutta-percha and sealer (fig. 20) Root canal treatment was completed by sealing the coronal access cavity using light curing composite resin and post-operative radiography (fig. 21).

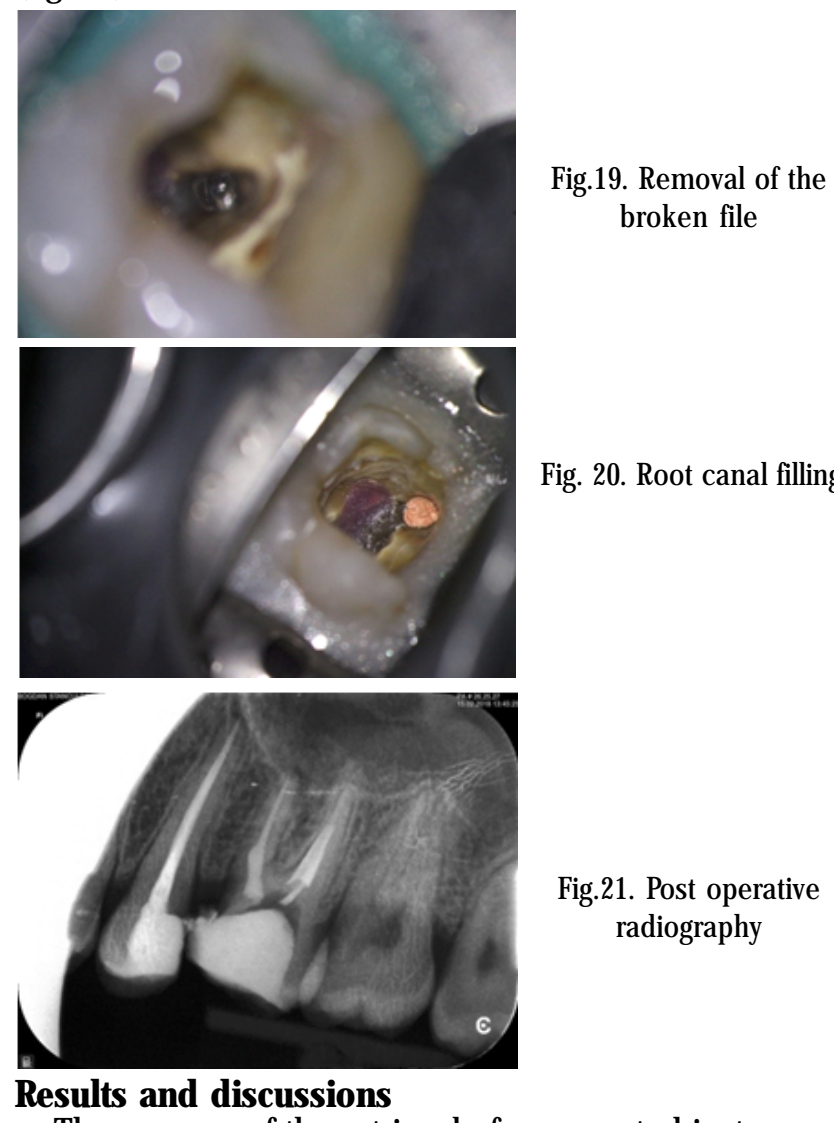

The success of the retrieval of a separated instrument depends on the canal anatomy, metallurgy of the broken file segment, location of the fragment inside the canal, the plane in which the canal curves, the length of the separated fragment and the diameter of the canal itself. The magnification and lighting is very important, the microscope provides options in magnification and coaxial light to promote superior vision [5].

The more apical the location of the fractured instrument the greater the potential for root perforation and the lower the fracture resistance of the root after the removal of the instrument. Straight line access is mandatory for successful removal of the instruments, butthe conservation of tooth structure is paramount to the tooth's resistance to fracture [6]. Also, it is known the saying if you can see it you can remove it. Gates Glidden drills should be limited to the straightaway portions of the canal with no effort made to carry then around the curve [7]. Sometimes the fractured section is apical, beyond the root curvature, and in such case microscopic retrieval (nonsurgical) is impossible [8]. Some studies, however, affirm that intracanal fragments with lengths more than $5 \mathrm{~mm}$ can be successfully removed from moderately curved canals [9]. 
The operating microscope in endodontics offers the great possibility to have a direct enhanced visualization of separated instruments in the root canal and by the use of fine ultrasonic tips or other specially designed instruments [10]. Direct visibility and creating a straight-line access increase the possibility to remove the instrument [11]. In the literature there are several studies that refer to another option of treatment, namely the bypass, [12] where you insert a fine file between the fragment and the root canal wall and you try to negotiate the canal to full working length and enable thorough instrumentation and root canal obturation with the fragment remaining in situ. Sometimes there is a risk of pushing the fragment out the root apex, with the consequence of periapical irritation [7]. Incorporating the fragment in the root canal obturation can improve the prognosis [13]. When the diagnose is acute periodontitis, and leakage and pain is still persistent it is recommended to use calcium hydroxide for about 14 days before the final root canal filling [14].

Some clinicians prefer using special extractors, custom made, and modified needles, instead of the ultrasonic tips, but such instruments require special skills from the operator, but once the technique is mastered itcan be time saving[15]. Others prefer using specialized instrumentretrieval kits, but they can be expensive, not always available and the dentist must know how to use it properly [16]. Therefore, in many cases, simple techniques are the best, sometimes even at use of general clinician [11].

Some studies contradict the hypothesis considering the momentum when the instrument broke inside the canal, meaning the status of the chemo-mechanical cleansing. Therefore, if the instrument broke at the beginning of the treatment, it is obstructing the root canal, not allowing complete chemo-mechanical disinfection the outcome will be significantly reduced. Obviously, it is wiser to prevent separation of instruments from occurring as attempting its retrieval is time consuming, involves potential complications, and may increase the anxiety levels of the patient. The prevention includes using new instruments, limited times re-sterilized, as the disinfectants and hot steam can alter the molecular structure, even more if the instrument has any fabrication faults $[17,18]$. The performance and mechanical properties of nickel-titanium instruments are influenced by factors such as crosssection, flute design, raw material, and manufacturing processes [19].

In case of using the bypass technique, it is important to be able to finish the proper chemical and mechanical treatment. The sealers and the obturation technique are also important for the final treatment outcome [20].

\section{Conclusions}

All our cases were a success, considering all broken intruments have been removed and the root canal treatment was redone, using rotative instruments and the filling was always radiologically verified. Overall, removing broken files from root canals can change the outcome, as some years ago the tooth, or at least the root, would have been compromised, but now the tooth can be saved with a good perspective in time.

\section{References}

1.LIN LM, SKRIBNER JE, GAENGLER P. J Endod. 18, no.12, 1992 p.625. 2.WADHAWAN R., LUTHRA K., KAUR S ] ., SOLANKI G. Br. J. mater Sci Technol 1, no.1, 2015, p. 1.

3.PARASHOS P., MESSER HH., J. Endod 32, no. 11, 2006, p. 1031

4.TOMER AK, MUNI S, BHARADWAJ G, MALIK N, Int J Oral Care Res, 4, no.1, 2016, p.75

5.RUDDLE CJ, Dent Today, 21, no. 7, 2002, p 70.

6.MCGUIGAN MB., LOUCA C., DUNCAN HF., Br Dent) , 214, no 8, 2013, p. 395

7.RUDDLE CJ., J Endod, 30, no.12, 2004, p. 827

8.RODA RS, GETTLEMAN BH. Non surgical retreatment. In: Hargeaves $K M$, Cohen S, eds. Pathways of the pulp, ed. 10, St Louis: Mosby; 2011, p. 890

9.SHEN Y, PENG B, CHEUNG GS, Oral Surg Oral Med Oral pathol Oral Radiol Endod, 98, no.5, 2004, p. 605

10.SUTER B, LUSSI A, SEQUEIRA P., J Endod, 38, no. 2, 2005, p. 112

11.ARCANJ O FROTA LM, ALMEIDA AGUIAR B, BRITO ARAGAO MG, DE VASCONCELOS BC, Case Rep Dent, 2016, ID 3970743, 2016, 4 p, http:/ /dx.doi.org/10.1155.2016/3970743

12.PRAVEEN S, HOSSAIN M, UDDIN F, Mujib med Univ, 10, no.1, 2017, p.41

13.SAUNDERS JL, ELEAZER PD, ZHANG P, MICHALEK S, J. Endod, 30, no.3, 2004, p.177

14.SOARES JA, BRITO-JUNIOR M, SILVEIRA FF, NUNES E, SANTOS SM. J Oral Sci, 50, no.1, 2008, p. 73

15.BRITO- JUNIOR M, NORMANHA JA, CAMILO CC, FARIA-E-SILVA AL, SAQUY PC, LEAO FERRAZ MAA, SILVA-SOUSA YTC, Brasil Dent J, 26, no.1, 2015, p. 79

16.NATANASABAPATHY V, SUNDAR S, KOTEESWARAN V, Endondology, 29, no1, 2017, p.65

17.SHEN Y1, HAAPASALO M, CHEUNG GS, PENG B. J Endod., 53, no. 1, 2009, p. 129

18.MCGUIGAN MB, LOUCA C, DUNCAN HF, Br Dent J, 214, vol. 6, 2013, p. 285 - 289

19.SHEN Y1, ZHOU HM, ZHENG YF, PENG B, HAAPASALO M. J. Endod., 39, no. 2013, p. 163

20.DIACONU, O., DASCALU, I.T., AMARASCU, M., MANOLEA, H.O., RICA, R., PETCU, C.M., TUCULINA, M.J., MORARU, A.I., Mat.Plast., 54, no 2,2017, p. 308-311

Manuscript received: 24.10 .2018 